\title{
JURISPRUDENCIA AMBIENTAL EN LA COMUNIDAD VALENCIANA (SEGUNDO SEMESTRE 2016)
}

\section{p. 1-3}

\section{JURISPRUDÈNCIA AMBIENTAL A LA COMUNITAT VALENCIANA (SEGON SEMESTRE 2016)}

$$
\text { p. 4-5 }
$$

\section{MARTA Oller Rubert}

Profesora contratada doctora de Derecho Administrativo/Professora contractada doctora de Dret Administratiu

Universitat Jaume I

\begin{abstract}
Sumario: 1. Declaración de interés comunitario: Sentencia del Tribunal Superior de Justicia de la Comunidad Valenciana 3135/2016, de 20 de mayo. 2. Restauración de la legalidad urbanística: Sentencia del Tribunal Superior de Justicia de la Comunidad Valenciana 3072/2016, de 20 de mayo.
\end{abstract}

\section{Declaración de interés comunitario: Sentencia del Tribunal Superior de Justicia} de la Comunidad Valenciana 3135/2016, de 20 de mayo

La finalidad de la declaración de interés comunitario (en adelante, DIC) es permitir determinados usos y aprovechamientos en suelos que no son urbanizables. Se trata, pues, de un instrumento que de forma excepcional permite el uso de suelos que por diversas circunstancias están preservados, de ahí su clasificación como "suelo rural". En este pronunciamiento el Tribunal Superior de Justicia de la Comunidad Valenciana conoce de un recurso de apelación interpuesto por la Generalitat (en adelante, GVA) contra una sentencia dictada por el Juzgado Contencioso-Administrativo de Alicante en el que se estimaba el recurso contencioso-administrativo presentado por una mercantil, A.C. Forint, S.A., frente a la resolución de la Secretaría Autonómica de Medio Ambiente, Agua, Urbanismo y Vivienda que desestimaba el recurso de alzada interpuesto por la empresa y que inadmitía a trámite la solicitud de DIC de una parcela declarada como 
"suelo no urbanizable de protección forestal y paisajística" y de "suelo no urbanizable de protección viaria" en donde se pretendía construir instalaciones para actividades formativas, alegándose incompatibilidad de usos.

A la vista de las pruebas presentadas por la mercantil y aceptadas por la GVA y por el Tribunal, queda claro que las instalaciones previstas no se incluyen dentro de la zona declarada "suelo no urbanizable de protección viaria", pero sí, sostiene la GVA, siguen estando incluidas en la zona de "suelo no urbanizable de protección forestal y paisajística", lo que continúa siendo motivo, en opinión de la GVA, para lo no concesión de la DIC, ya que esta solo puede concederse en el caso de suelo no urbanizable común, según establecía la Ley 10/2004, de 9 de diciembre, de la Generalitat, del Suelo no Urbanizable. No obstante, como aprecia el Tribunal Superior de Justicia de la Comunidad Valenciana en su FJ 4. ${ }^{\text {o }}$, existe una previsión excepcional en el artículo 32 de la citada Ley 10/2004 que permite usos y aprovechamientos en los suelos rurales protegidos si existe información favorable de la conselleria competente en materia de espacios naturales, previsión que también recoge la legislación estatal de suelo de 2008. Sobre la base de lo anterior, el Tribunal Superior de Justicia de la Comunidad Valenciana señala que, en cualquier caso, en el supuesto planteado no es necesaria ni siquiera una DIC, sino que basta con el informe favorable apuntado, informe que realizó el jefe del Servicio de Parques Naturales de la Dirección General de Planificación y Ordenación Territorial en 2006, el cual exigía, para legalizar dichas actividades compatibles, una estimación del impacto ambiental y un estudio de paisaje.

El fallo final del Tribunal Superior de Justicia de la Comunidad Valenciana determina en primer lugar que las instalaciones previstas sí que son compatibles con las normas de planeamiento urbanístico y que no es necesaria una DIC, sino que se requiere, conforme hemos destacado respecto al informe favorable otorgado en 2006, que se lleven a cabo las actividades de compatibilidad ambiental señaladas, por lo que se realiza una estimación parcial del recurso presentado. 


\section{Restauración de la legalidad urbanística: Sentencia del Tribunal Superior de} Justicia de la Comunidad Valenciana 3072/2016, de 20 de mayo

Es un caso de restauración de la legalidad urbanística en el que se plantea un posible exceso en la realización de obras amparadas en una DIC concedida a un camping que, ante el incremento de la demanda turística, realiza una ampliación de servicios e instalaciones y pide la ampliación de la DIC concedida en el año 2000, solicitud que fue inadmitida por la Administración autonómica. Al respecto, y alegando ilegalidad por no contar con las autorizaciones preceptivas, la Dirección General de Evaluación Ambiental dicta una resolución que obliga a desmontar y demoler las instalaciones construidas en exceso, frente a lo que la demandante, ESTIVELLA LES CONQUES PARK, S. L., interpone un recurso administrativo de alzada que también es desestimado, por lo que finalmente plantea el presente recurso contencioso-administrativo ante el Tribunal Superior de Justicia de la Comunidad Valenciana. La pretensión del recurso es la anulación de la desestimación. Sin embargo, tras el estudio de las alegaciones, el TSJ de la Comunidad Valenciana, además de estimar que se ha producido una desviación procesal del objeto del recurso en el escrito de demanda porque no existe DIC, puesto que hubo una inadmisión, señala en su FJ 2. ${ }^{\circ}$, último párrafo, que, para realizar obras de ampliación, es necesario solicitar y obtener la DIC. 
Sumari: 1. Declaració d'interès comunitari: Sentència del Tribunal Superior de Justícia de la Comunitat Valenciana 3135/2016, de 20 de maig. 2. Restauració de la legalitat urbanística: Sentència del Tribunal Superior de Justícia de la Comunitat Valenciana 3072/2016, de 20 de maig.

\section{Declaració d'interès comunitari: Sentència del Tribunal Superior de Justícia de la Comunitat Valenciana 3135/2016, de 20 de maig}

La finalitat de la declaració d'interès comunitari (d'ara endavant DIC) és permetre determinats usos i aprofitaments en sòls que no són urbanitzables. Es tracta, doncs, d'un instrument que de forma excepcional permet l'ús de sòls que, per diverses circumstàncies, estan preservats; d'aquí els ve la classificació com a "sòl rural". En aquest pronunciament, el Tribunal Superior de Justícia de la Comunitat Valenciana coneix d'un recurs d'apel·lació interposat per la Generalitat (d'ara endavant GVA) contra una sentència dictada pel Jutjat Contenciós Administratiu d'Alacant en el qual s'estimava el recurs contenciós administratiu presentat per una mercantil, AC Forint, SA, enfront de la resolució de la Secretaria Autonòmica de Medi Ambient, Aigua, Urbanisme i Habitatge que desestimava el recurs d'alçada interposat per l'empresa i que inadmetia a tràmit la sol-licitud de DIC d'una parcel·la declarada com a "sòl no urbanitzable de protecció forestal i paisatgístic" i de "sòl no urbanitzable de protecció viària", on es pretenia construir instal·lacions d'activitats formatives, al·legant incompatibilitat d'usos.

A la vista de les proves presentades per la mercantil i acceptades per la GVA i pel Tribunal, queda clar que les instal-lacions previstes no s'inclouen dins de la zona declarada "sòl no urbanitzable de protecció viària", però sí que, com sosté la GVA, continuen incloses a la zona de "sòl no urbanitzable de protecció forestal i paisatgístic", la qual cosa continua essent motiu, a entendre de la GVA, per a la no-concessió de la DIC, ja que aquesta solament pot concedir-se en el cas de sòl no urbanitzable comú, segons establia la Llei 10/2004, de sòl no urbanitzable. No obstant això, com aprecia el Tribunal Superior de Justícia de la Comunitat Valenciana en el FJ 4, existeix una previsió excepcional en l'article 32 de l'esmentada Llei 10/2004 que permet usos i aprofitaments en els sòls rurals protegits sí hi ha informació favorable de la conselleria competent pel que fa a espais naturals, previsió que també recull la legislació estatal de sòl de 2008. Segons el que hem dit anteriorment, el Tribunal Superior de Justícia de la Comunitat Valenciana assenyala que en qualsevol cas, en el supòsit plantejat no cal ni tan sols una DIC, sinó que n'hi ha prou amb l'informe favorable apuntat, informe que va elaborar el cap de servei de Parcs Naturals de la Direcció General de Planificació i Ordenació 
Territorial el 2006, però que exigeix, en qualsevol cas, per a la legalització d'aquestes activitats compatibles, l'estimació de l'impacte ambiental i l'estudi de paisatge.

La resolució final del Tribunal Superior de Justícia de la Comunitat Valenciana determina, en primer lloc, que les instal·lacions previstes sí que són compatibles amb les normes de planejament urbanístic, però que cal una DIC; sinó que es requereix, d'acord amb el que hem destacat pel que fa a l'informe favorable atorgat el 2006, que es duguin a terme les activitats de compatibilitat ambiental assenyalades, per la qual cosa es du a terme l'estimació parcial del recurs presentat.

\section{Restauració de la legalitat urbanística: Sentència del Tribunal Superior de} Justícia de la Comunitat Valenciana 3072/2016, de 20 de maig

És un cas de restauració de la legalitat urbanística en el qual es planteja un possible excés en la realització d'obres emparades en una DIC concedida, en aquest cas, a un càmping que, davant l'increment de la demanda turística, fa una ampliació de serveis i instal-lacions, i demana l'ampliació de la DIC concedida l'any 2000, sol·licitud que va ser inadmesa per l'Administració autonòmica. Sobre aquest tema i al-legant il-legalitat per no haver disposat de les autoritzacions preceptives, la Direcció General d'Avaluació Ambiental dicta una resolució que obliga a desmuntar i demolir les instal-lacions construïdes a l'excés. Davant d'això, la demandant, ESTIVELLA LES CONQUES PARK, SL, interposa un recurs administratiu d'alçada que també és desestimat, per la qual cosa, la mercantil ESTIVELLA LES CONQUES PARK, SL planteja el present recurs contenciós administratiu davant el Tribunal Superior de Justícia de la Comunitat Valenciana. La pretensió del recurs és l'anul·lació de la desestimació. No obstant això, després de l'estudi de les al·legacions, el TSJ de la Comunitat Valenciana, a més d'estimar que hi ha hagut una desviació processal de l'objecte del recurs en l'escrit de demanda, perquè no existeix DIC, ja que va haver-hi una inadmissió, el Tribunal insisteix en el seu FJ 2, en l'últim paràgraf, que, per dur a terme obres d'ampliació, cal haver sol-licitat i obtingut la DIC. 